\title{
Sudden cardiac death: An autopsy study
}

\author{
Gireesh V. Achalkar \\ Associate Professor, Dept. of Pathology, Raichur Institute of Medical Sciences, Raichur, Karnataka, India
}

*Corresponding Author:

Email: drgireesha@yahoo.com

\begin{abstract}
Introduction: The most common cause of sudden cardiac death is ischaemic. Such patients may have an occlusive recent thrombosis in one or more major coronary arteries. An area of stenosis of 85 per cent is the best discriminating level for increased mortality.

Objective: To study the cardiac causes of sudden death.

Materials and Methods: 200 medicolegal cases of sudden death requested for pathological examination of heart were studied. A careful study of the information given by the police and forensic medicine experts was done. The heart was examined macroscopically for clots, thrombi, any anomalies, tumors or any other pathological signs. The sections of the organ were studied.

Results: A total of 200 cases were studied with 120 males and 80 females. Majority of them (70\%) weighed less than 300 grams. Only 2 weighed more than 350 grams. Cardiomyopathies were recognized in 30 specimen. Dilated cardiomyopathy was most common among them and accounted for 20 cases.

Conclusion: Personal experience of studying such patients, suggests that the majority of deaths are indeed cardiac. The various causes of sudden cardiac death must be correlated with pathological findings to arrive at a definitive diagnosis.
\end{abstract}

Keywords: Autopsy, Heart, Ischemia, Thrombosis, Ventricular fibrillation.

\section{Introduction}

The most common cause of sudden cardiac death is

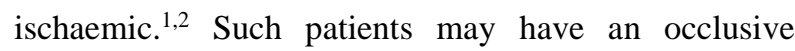
recent thrombosis in one or more major coronary arteries. An area of stenosis of $85 \%$ is the best discriminating level for high mortality. ${ }^{2}$ Most subjects who die of ischaemic heart disease suddenly, have this degree of stenosis in two or three major arteries. ${ }^{3,4}$ Severe aortic stenosis, hypertrophic and obstructive cardiomyopathy are non ischemic causes for sudden death. ${ }^{5}$ When the heart is macroscopically normal, review of previous electrocardiograms is the most helpful guide and may disclose conditions such as a long QT interval or pre-excitation. Use of the term "cardiomyopathy" by pathologists to cover all nonischaemic sudden cardiac death is clinically misleading. The pathologist, investigating sudden cardiac death in an adult or a child over 1 year of age, can usually place the heart into one of three categories. ${ }^{6-8}$ In order of frequency these are ischaemic heart disease, conditions recognized macroscopically known to be associated with sudden death and, finally, hearts which are, at least to the naked eye, normal. , $^{9,10}$

Annually many thousands of patients dying suddenly from ischaemic heart disease undergo autopsy for examination by forensic experts and pathologists. ${ }^{11,12}$ There is surprisingly little knowledge known of the pathology of ischaemic heart disease related to sudden death. ${ }^{13}$

A proportion of these patients do have a recent occlusive thrombus in a major coronary artery. Atherosclerosis with fibrofatty atheroma is a common finding in coronary arteries. Death can be assumed to be from subsequent ventricular fibrillation. ${ }^{14,15}$ The proportion of cases with such a thrombus is reported to be from 4 to64 per cent. ${ }^{15}$ Such widely divergent figures reflect, in part, the degree of care taken or the beliefs of the individual pathologist.

Even within a single pathological department the proportion of thrombi found by different individual consultant pathologists varies widely. ${ }^{16}$ Other factors which militate against comparability of series are different temporal definitions of the term "sudden", varying proportions of smokers to non-smokers. ${ }^{17,18}$

\section{Objective}

To study the cardiac causes of sudden death.

\section{Materials and Methods}

200 medicolegal cases of sudden death requested for pathological examination of heart were studied at RIMS, Raichur from Jan 2016 to June 2018. A careful study of the information given by the police and forensic medicine experts was done. The heart was examined macroscopically for clots, thrombi, any anomalies, tumors or any other pathology. The organ was dissected in the direction of flow of blood. Multiple bits were taken from left anterior descending coronary artery, right coronary and left circumflex coronary artey. Bits were also taken from ventricles, valves, root of aorta and pericardium. Sections were taken and stained with $\mathrm{H} \& \mathrm{E}$, and special stains like congo red and others. Sections were studied under the microscope. 


\section{Results}

A total of 200 cases were studied. 120 were male and 80 were female. (Table 1) Majority of them (70\%) weighed less than 300 grams. Only 2 weighed more than 350 grams. (Table 2). Cardiomyopathies were recognized in 30 specimen. Dilated cardiomyopathy was most common among them and accounted for 20 cases. (Table3) Coronary vessels showed macroscopic thrombi in 80 of them. (Table 4). Microscopic examination of coronary vessels revealed atherosclerosis in 150 specimen. 100 were complicated by thrombi. Non ischemic causes including hypertrophic cardiomyopathy (HOCM) accounted for lesser numbers of cases (Table 5).

Table 1: Gender distribution

\begin{tabular}{|l|c|c|}
\hline \multicolumn{1}{|c|}{ Gender } & No. & \% \\
\hline Male & 120 & 60 \\
\hline Female & 80 & 40 \\
\hline Total & 200 & 100 \\
\hline
\end{tabular}

Table 2: Weight of heart

\begin{tabular}{|l|c|c|}
\hline \multicolumn{1}{|c|}{ Weight } & No. & \% \\
\hline$<300 \mathrm{~g}$ & 140 & 70 \\
\hline $300-350 \mathrm{~g}$ & 58 & 29 \\
\hline$>350 \mathrm{~g}$ & 02 & 01 \\
\hline Total & 200 & 100 \\
\hline
\end{tabular}

Table 3: Cardiomyopathies

\begin{tabular}{|l|c|c|}
\hline \multicolumn{1}{|c|}{ Type } & No. & \% \\
\hline Dilated & 20 & 66.6 \\
\hline Restrictive & 05 & 16.6 \\
\hline Hypertrophic & 05 & 16.6 \\
\hline Total & 30 & 100 \\
\hline
\end{tabular}

Table 4: Macroscopic Thrombi in coronary vessels

\begin{tabular}{|l|c|c|}
\hline \multicolumn{1}{|c|}{ Lesion } & No. & $\mathbf{\%}$ \\
\hline Seen & 80 & 40 \\
\hline Not seen & 120 & 60 \\
\hline Total & 200 & 100 \\
\hline
\end{tabular}

Table 5: Microscopic atherosclerosis in coronary vessels

\begin{tabular}{|l|c|c|}
\hline \multicolumn{1}{|c|}{ Lesion } & No. & \% \\
\hline Present & 150 & 75 \\
\hline Absent & 50 & 25 \\
\hline Total & 200 & 100 \\
\hline
\end{tabular}

\section{Discussion}

To demonstrate a morphological cause for sudden death is the wish of many pathologists. ${ }^{19,20}$ The reported proportion of patients dying with ischaemic heart disease is very wide, from 12 to 85 per cent. ${ }^{3,21,22}$ The cases with an occlusive thrombus can be predicted to develop regional myocardial infarction ${ }^{23,24}$ but when death occurs within12 hours it is difficult for the pathologist to demonstrate necrosis. ${ }^{25}$ Figures from Seattle ${ }^{26}$ indicate that only 19 per cent of patients resuscitated from "sudden death" do develop myocardial infarction

The occlusion when present does, however, act as a trigger to provoke ventricular fibrillation. ${ }^{27,28}$

Platelet emboli are postulated to cause sudden death. ${ }^{29-31}$ It is certainly possible that a shower of disintegrating platelets may not only block small arteries but their "pharmacological" contents could provoke intense spasm more distally. ${ }^{32,33}$ There is some evidence suggesting that right coronary artery occlusions are more often associated with sudden death. ${ }^{34,35}$ The limited published data available suggest that the ratio of right to left anterior descending artery occlusions is lower in patients dying in hospital of infarction than sudden death patients not reaching hospital. ${ }^{36,37}$ (Table 6).

Table 6: Frequency of recent occlusive coronary thrombosis in sudden death

\begin{tabular}{|c|c|c|}
\hline Author & No. of cases & Thrombosis \% \\
\hline 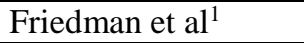 & 27 & 4 \\
\hline Kuller et $\mathrm{al}^{2}$ & 486 & 18 \\
\hline Lie and Titus ${ }^{3}$ & 120 & 17 \\
\hline Spain \&Bradess ${ }^{4}$ & 189 & 18 \\
\hline Titus et $\mathrm{al}^{5}$ & 286 & 19 \\
\hline Perper et $\mathrm{al}^{6}$ & 171 & 22 \\
\hline Davies and popple ${ }^{10}$ & 120 & 33 \\
\hline Baba et $^{111}$ & 121 & 38 \\
\hline Crowford et al ${ }^{12}$ & 75 & 64 \\
\hline Present study & 200 & 40 \\
\hline
\end{tabular}

James $^{29,30}$ has reviewed the possible causes of this association which leads the right coronary to be regarded as the artery of sudden death. ${ }^{38}$ The major factor is the role of the right coronary artery in supplying both sinuatrial and atrioventricular nodes. ${ }^{39,40}$ 
The role of pure coronary artery spasm is clearly not amenable to investigation in the dead heart and must remain speculative. ${ }^{41,42}$

Table 7: Site of occlusive coronary thrombosis in sudden death

\begin{tabular}{|l|c|c|c|c|c|}
\hline \multicolumn{1}{|c|}{ Author } & No. & Main left & LAD & RCA & LCX \\
\hline Friedman et al $^{1}$ & 21 & 01 & 11 & 07 & 02 \\
\hline $\begin{array}{l}\text { Davies and } \\
\text { Popple }^{10}\end{array}$ & 39 & 00 & 18 & 16 & 09 \\
\hline Crowford et al $^{12}$ & 48 & 00 & 27 & 15 & 06 \\
\hline Basha et al $^{11}$ & 46 & 03 & 16 & 19 & 08 \\
\hline Present study & 80 & 02 & 38 & 26 & 14 \\
\hline
\end{tabular}

Cardiac death not caused by coronary atheroma: The second major group of hearts are those with nonischaemic cardiac disease. ${ }^{43,44}$ Severe left ventricular hypertrophy particularly due to aortic valve stenosis may be associated with sudden death. ${ }^{45}$ In practice, hearts of a total weight over $550 \mathrm{~g}$ will have sufficient ventricular hypertrophy to be reasonably associated with sudden death. ${ }^{46}$ In cases of aortic stenosis, subendocardial recent necrosis is usually demonstrable in the left ventricle. Gross right ventricular hypertrophy also carries a risk of sudden death usually associated with previously unrecognized pulmonary valve stenosis, obstructive cardiomyopathy, or primary pulmonary hypertension. ${ }^{47-49}$

Sudden death is seen particularly in men (Table 4) and has been reported to occur particularly in certain families. $^{37,38}$ There are no morphological features to distinguish those cases dying suddenly from those not. The pathologist should suspect hypertrophic cardiomyopathy in any heart showing ventricular hypertrophy with a small left ventricular cavity. Inclusion as a standard autopsy practice of measurement of the septum and posterior wall with ratios over 1.6 confirms many of these cases to be hypertrophic cardiomyopathy. $^{38}$ (Table 5). In hypertrophic cardiomyopathy gross hypertrophy of the free left ventricular wall, on occasions, tends to mask the septal asymmetric hypertrophy leading to an erroneous diagnosis of "hypertensive" cardiomegaly. ${ }^{50}$

On rare occasions the mass of abnormal muscle is not septal. A reversal of the septal/posterior wall ratio may also therefore indicate hypertophic cardiomyopathy provided that no old septal infarction is present. ${ }^{40}$ Subaortic endocardial thickening is always a valuable confirmatory feature in cases of HOCM with outflow obstruction. Cardiomyopathy of the congestive form is not associated to any obvious degree with sudden death without a prior long period of left ventricular failure. ${ }^{51}$

Deposition of amyloid can cause sudden death particularly when extensive and involving the conduction system. ${ }^{52,53} \mathrm{~A}$ high proportion of elderly patients at autopsy have nodules of a substance staining as amyloid in the left atrium with a tendency to be associated with atrial fibrillation. ${ }^{4,54}$
Acute myocarditis of all forms can be associated with sudden death ${ }^{55-57}$ with history of some days' malaise, fever, and tachycardia or palpitation. It is possible to suspect the diagnosis macroscopically; the myocardium is mottled, the left ventricle dilated but with no cardiomegaly. Pericarditis is also present. Idiopathic giant cell myocarditis has serpiginous areas of myocardial necrosis. ${ }^{58}$ Myocardial sarcoidosis is easily confirmed histologically.

Once again caution must be used to avoid overdiagnosis of myocarditis at autopsy. ${ }^{59,60}$ Isolated foci of lymphocytes in the atrial myocardium are common in all elderly hearts and may be erroneously related to death by pathologists. In cases of death actually caused by myocarditis virtually every histological block from the ventricular muscle, and often from the conduction system itself, is involved. ${ }^{60}$

Sudden death may occur in patients with floppy mitral valves, yet without severe mitral regurgitation. ${ }^{61,62}$ The frequency of the valve abnormality in the population is of the order of 5 per cent $^{42,63}$ so the risk of death to any individual patient with a floppy mitral valve must be very small. ${ }^{43,44}$ Patients with a mild floppy valve and a normal electrocardiogram probably have no such risk. The mechanism underlying these electrocardiographic abnormalities is debatable. ${ }^{46,64}$ It has been ascribed to be associated with a primary muscle abnormality, mechanical traction on papillary muscles, endocardial impact with the valve, anomalous coronary arteries, and interference with left circumflex flow. ${ }^{65-67}$ If this is a subtle abnormality of myocardial repolarisation, it is uncertain if the association with a floppy mitral valve is fortuitous.

Anomalous coronary artery anatomy ${ }^{47,68}$ may be perfectly benign or produce serious functional effects. Where the abnormality is a simple one of both coronary orifices arising from the same sinus or a single orifice there is no risk of sudden death.

The commonest form is to find a single or two orifices in the right coronary sinus. ${ }^{69}$ The left anterior descending coronary artery crosses in front of the right ventricular outflow..$^{70,71}$

Sudden death is a risk either when a segment of the coronary artery tree is aplastic or when there is a 
coronary shunt. Most frequently the former is a single right coronary orifice with the left anterior descending artery passing behind the pulmonary artery and being represented as a fibrous strand without a lumen. ${ }^{72,73}$ Coronary shunts occur with a fistula from an artery into the ventricles, atria, or coronary sinus. Aneurysmal dilatation of the coronary artery involved ensues and myocardial perfusion becomes abnormal. Anomalous origin of one coronary artery from the pulmonary artery also leads to an aortic-pulmonary shunt. ${ }^{74,75}$ Coronary embolism is a cause of sudden death. Emboli occur most frequently from aortic valve thrombus as in bacterial endocarditis. All myxomatous polyps on the aortic valve may prolapse into a coronary orifice but are extremely rare..$^{9}$ Isolated dissection of coronary arteries occurs occasionally to produce sudden death in Marfan's syndrome and also in pregnancy. . $^{50,51,76}$

Coronary arteritis occurs in polyarteritis nodosa ${ }^{52,77}$ and sudden death is well described. ${ }^{19}$ In $\operatorname{Japan}^{78}$ a striking syndrome of lymphadenopathy, skin rash, conjunctivitis, and fever in young children with a high risk of sudden death from coronary arteritis is relatively common $^{63,79}$ When all other known causes of sudden death have been excluded macroscopical examination of the area of the conduction system is, on occasion, helpful. The small benign mesothelial tumour of the atrioventricular node ${ }^{54,56}$ is usually visible as a 1 to 2 $\mathrm{cm}$ cystic mass in the atrial septum anterior to the coronary sinus. It is when the pathologist is faced with a heart apparently totally normal to external examination that practical problems arise. ${ }^{80}$

A number of conditions deserving better recognition is also squeezed into a "cardiomyopathy" group by pathologists. Isolated increase in the heart weight is better termed idiopathic cardiomegaly. Most examples are probably an excessive hypertrophy response to unrecorded hypertension. ${ }^{81}$

Widespread interstitial or focal myocardial fibrosis without other morphological abnormality is best termed idiopathic myocardial scarring and may well be due to post-viral myocarditis. This group of patients, clinically, may be associated with arrhythmic problems entirely without evidence of abnormal myocardial contractile function. ${ }^{82}$

Macroscopically, normal hearts are also encountered in which a selective and progressive loss of conduction fibres occurs followed by replacement fibrosis. These hearts are again not associated with evidence of loss of contractile function but develop arrhythmias and conduction defects. ${ }^{83}$

\section{Conclusion}

The initial step is to exclude unnatural death, in particular a concealed suicide. Blood should be screened for drugs by gas chromatography. After these steps have been carried out death can be presumed to be cardiac in origin. A detailed medical history from the family has to be sought and any electrocardiogram ever taken must be reviewed. The conduction system has to be examined histologically. Personal experience of studying such patients, suggests that the majority of deaths are indeed cardiac. The various causes of sudden cardiac death must be correlated with pathological findings to arrive at a definitive diagnosis.

\section{Acknowledgements}

I am grateful and thankful to our Dean cum Director for the support and encouragement.

I thank Department of Forensic Medicine without whom this project would have been impossible.

I would like to thank my colleagues and technicians for their wonderful collaboration.

Funding: No funding sources.

Conflict of interest: None declared.

\section{References}

1. Friedman M, Manwaring JH, Rosenman RH, Donlon G, Ortego P, Grube SM. Instantaneous and sudden deaths: clinical and pathological differentiation in coronary artery disease. JAMA 1973;225:1319-28.

2. Kuller LH, Cooper M, Perper J, Fisher R. Myocardial infarction and sudden death in an urban community. Bull NY Acad Med 1973;49:532-43.

3. Lie JT, Titus JL. Pathology of the myocardium and the conduction system in sudden coronary death. Circulation 1975;51 and 52(suppl 3):41-52.

4. Spain DM, Bradess VA. Sudden death from coronary heart disease. Survival time, frequency of thrombi and cigarette smoking. Chest 1970;58:107-10.

5. Titus JL, Oxmnan HA, Connolly DC, and Nobrega FT. Sudden unexpected death as the initial manifestation of coronary heart disease. Clinical and pathological observations. Singapore Med J 1973;14:291-93.

6. Perper JA, Kuller LH, Cooper M. Arteriosclerosis of coronary arteries in sudden unexpected deaths. Circulation 1975;51 and 52(suppl 3):27-33.

7. Haerem JW. Mural platelet microthrombi and major acute lesions of main epicardial arteries in sudden death. Atherosclerosis 1974;19:529-41.

8. Myers A, Dewar HA. Circumstances attending 100 sudden deaths from coronary artery disease with coroner's necropsies. Br Heart J 1975;37:1133-43.

9. Mitchell JRA, Schwartz CJ. Arterial disease. Oxford: Blackwell, 1965.

10. Davies MJ, Popple AW. Sudden unexpected cardiac death-a practical approach to the forensic problem. Histopathol 1979;3:255-77.

11. Baba N, Bashe WJ Jr, Keller MD, Geer JC, Anthony JR. Pathology of atherosclerotic heart disease in sudden death. I. Organising thrombus and acute coronary vessel lesions. Circulation 1975;51 and 52(suppl 3):53-9.

12. Rissanen V, Romo M, Siltanen P. Prehospital sudden death from ischaemic heart disease-a postmortem study. Br Heart J 1978;40:1025-33.

13. Scott RG, Briggs RS. Pathological findings in prehospital deaths due to coronary atherosclerosis. Am J Cardiol 1972;29:782-87.

14. CotranRS,Kumar V ,Robbins: Pathologic basis of Disease 2010 Sounders.

15. Fulton W: Pathologic concepts in acute coronary thrombosis: relevance to treatment. Br Heart J 1993;70:403. 
16. Ross R. Pathogenesis of Atherosclerosis: A perspective for the 1990s. Nature 1993;362:801.

17. Jennings R, Riemer K. Lethal myocardial ischemic injury. Am J Pathol 1981;102:241.

18. Thompson R. Isolated coronary ostial stenosis in women. J Am Coll Cardiol 1987;760:28.

19. Dellborg M. Rupture of myocardium: Occurance and Risk factors. Br Heart J 1987;54:11.

20. Barbour D. Rupture of a left ventricular papillary muscle during Acute myocardial infarction. J Am Coll Cardiol 1986;8:548.

21. Roberts W. Calcification of healed myocardial infarct. Am J Cardiol 1987;60:28.

22. Fowler NO. Tuberculous Pericarditis: JAMA 1991;266:99.

23. Lam KL. Tumors of Heart: Arch Pathol Lab Med 1993;117:1027.

24. Liberthson RR, Nagel EL, Hirschman JC, Nussenfeld SR, Blackborne BD, Davies JH. Pathophysiologic observations in pre-hospital ventricular fibrillation and sudden cardiac death. Circulation 1974;49:790-8.

25. Crawford T, Dexter D, Teare RD. Coronary artery pathology in sudden death from myocardial ischaemia. Lancet 1961;1:181-5.

26. Davies MJ, Woolf N, Robertson WB. Pathology of acute myocardial infarction with particular reference to occlusive coronary thrombi. Br Heart J 1976;38:659-64.

27. Blotz M. Coronary heart disease. London: Cassell 1957.

28. Bashe WJ Jr, Baba N, Keller MD, Geer JC, Anthony JR. Pathology of atherosclerotic heart disease in sudden death. II. The significance of myocardial infarction. Circulation 1975;52(suppl 3):63-77.

29. James TN. De subitaneis mortibus. XXVII. Apoplexy of the heart. Circulation 1978;57:91-94 Pathological view of sudden cardiac death.

30. James TN. Pathogenesis of arrhythmias in acute myocardial infarction. Am J Cardiol 1969;24:791-99.

31. Baum RS, Alvarez H III, Cobb LA. Survival after resuscitation from out of hospital ventricular fibrillation. Circulation 1974;50:1231-35.

32. Scahffer WA, Cobb LA. Recurrent ventricular fibrillation and modes of death in survivors of outofhospital ventricular fibrillation. $N$ Engl J Med 1975;293: 259-62.

33. Bleifer SB, Bleifer DJ, Hansmann DR, Sheppard JJ, Karpman HL. Diagnosis of occult arrhythmias by Holter electrocardiography. Prog Cardiovasc Dis 1974;16:56999.

34. Pool J, Kunst K, Van Wermeskerken JL. Two monitored cases of sudden death outside hospital. Br Heart J 1978;40:627-9.

35. Gradman AH, Bell PA, DeBusk RF. Sudden death during ambulatory monitoring; clinical and electrocardiographic correlations. Report of a case. Circulation 1977;55:210-1.

36. Cobb LA, Hallstrom AP, Weaver DW, Copass MK, Haynes RE. Clinical predictors and characteristics of the sudden cardiac death syndrome. Proceedings first US/USSR symposium on sudden death. Yalta, 1977. US Public Health Service. NIH Publ No. 78-1470, 1978, 99116.

37. Lown B. Sudden cardiac death: the major challenge confronting contemporary cardiology. Am J Cardiol 1979;43:313-28.

38. Crawford MD, Clayton DG, Stanley F, Shaper AG. An epidemiological study of sudden death in hard and soft water areas. J Chronic Dis 1977;30:69-80.
39. Crawford T, Crawford MD. Prevalence and pathological changes of ischaemic disease in a hard and in a soft water area. Lancet 1967;1:229-32.

40. Anderson TW, LeRiche WH, Mackay JS. Sudden death in ischaemic heart disease; correlation with hardness of local water supply. N Engl J Med 1969;280:805-7.

41. Chipperfield B, Chipperfield JR. Relation of myocardial metal concentration to water hardness and death rates from ischaemic heart disease. Lancet 1979;2:709-12.

42. Reichenbach DD, Moss NS. Myocardial necrosis and sudden deaths in humans. Circulation 1975;51 and 52(suppl 3):60-2.

43. Fulton WFM. The coronary artery-arteriography, microanatomy and pathogenesis of obliterative coronary artery disease. Springfield, Illinois: Charles C Thomas, 1965.

44. Frink RJ, Trowbridge JO, Rooney PA Jr. Nonobstructive coronary thrombosis in sudden cardiac death. Am J Cardiol 1978;42:48-51.

45. Hellstrom RA. Evidence in favour of the vasospastic cause of coronary artery thrombosis. Am Heart $J$ 1979;97:449-52.

46. Lancet. Editorial. Scottish hearts. 1979;2:726-7.

47. Maron BJ, Roberts WC, Edwards JE, McAllister HA, Foley DD, Epstein SE. Sudden death in patients with hypertrophic cardiomyopathy: characterization of 26 patients without functional limitation. Am J Cardiol 1978;41:803-10.

48. Maron BJ, Lipson LC, Roberts EC, Savage DD, Epstein SE. Malignant hypertrophic cardiomyopathy: identification of a sub-group of families with unusually frequent premature death. Am J Cardiol 1978;41:113340.

49. Spray TL, Marron BJ, Morrow AG, Epstein SE, Roberts WC. A discussion on hypertrophic cardiomyopathy. Am Heart J 1978;95:511-20.

50. Noakes TD, Rose AG, Opie LH. Hypertrophic cardiomyopathy associated with sudden death during marathon racing. Br Heart J 1979;41:624-27.

51. Pomerance A. Infiltrations and storage diseases. In: Pomerance A, Davies MJ, eds. Pathology of the heart. Oxford: Blackwell, 1975.

52. Davies MJ, Moore BP, Braimbridge MV. The floppy mitral valve-a study of incidence pathology and complications in surgical necropsy and forensic material. Br Heart J 1978;40:468-81.

53. Campbell RWF, Godman MG, Fiddler GI, Marquis RM, Julian DG. Ventricular arrhythmias in syndrome of balloon deformity of mitral valve. Definition of possible high risk group. Br Heart J 1976;38:1053-7.

54. Krikler D, Curry P, Kafetz K. Preexcitation and mitral valve prolapse. Br Med J 1976;1:1257.

55. Josephson ME, Harowitz LN, Kastor JA. Paroxysmal supraventricular tachycardia in patients with mitral valve prolapse. Circulation 1978;57:111-5.

56. Leichtman D, Nelson R, Gobel FL, Alexander CS, Cohn JN. Bradycardia with mitral valve prolapse-a potential mechanism of sudden death. Ann Intern Med 1976;85:453-57.

57. Ogden JA. Congenital anomalies of the coronary arteries. Am J Cardiol 1970;25:474-9.

58. Heggveit HA. Syphilitic aortitis-a clinicopathological autopsy of 100 cases. Circulation 1964;29: 346-55.

59. Harris LS, Adelson L. Fatal coronary embolism from a myxomatous polyp of the aortic valve. An unusual cause of sudden death. Am J Clin Pathol 1965;43:61-4.

60. Guthrie W, Maclean H. Dissecting aneurysms of arteries other than the aorta. J Pathol 1972;108:219-35. 
61. Shaver PJ, Carrig TF, Baker WP. Postpartum coronary artery dissection. Br Heart J 1978;40:83-6.

62. Thiene G, Valente M, Rossi L. Involvement of the cardiac conduction system in panarteritis nodosa. $A m$ Heart J 1978;95:716-24.

63. Kegel SM, Dorsey TJ, Rowen M, Taylor WF. Cardiac death in mucocutaneous lymph node syndrome. Am J Cardiol 1977;40:282-86.

64. James TN, Galakov I. De subitaneis mortibus. XXVI. Fatal electric instability of the heart associated with benign congenital polycystic tumour of the atrioventricular node. Circulation 1977;56:667-78.

65. Bharati S, Bicoff JP, Fridman JL, Lev M, Rosen KM. Sudden death caused by benign tumour of the atrioventricular node. Arch Intern Med 1976;136:224-28.

66. Becker AE, Anderson RH, Durrer D, Wellens HJJ. The anatomic substrates of the Wolff-Parkinson-White syndrome. A clinicopathological correlation in seven patients. Circulation 1978;57:870-79.

67. Johansson BW, Jorming B. Hereditary prolongation of the QT interval. Br Heart J 1972;34:744-51.

68. Moothart RW, Pryor R, Hawley RL, Clifford NJ, Blount SG Jr. The heritable syndrome of prolonged QT interval, syncope, and sudden death. Electron microscopic observation. Chest 1976;70:263-6.

69. James TN, Froggatt P, Atkinson WJ Jr, et al. De subitaneis mortibus. XXX. Observations on the pathophysiology of the long QT syndromes with special reference to the neuropathology of the heart. Circulation 1978;57:1221-31.

70. Davies MJ, Harris A. Pathological basis of primary heart block. Br Heart J 1969;31:219-26.

71. Lev M. The pathology of complete atrioventricular block. Progr Cardiovasc Dis 1964;6:317-26.

72. Lenegre J. Etiology and pathology of bilateral bundle branch block in relation to complete heart block. Progr Cardiovasc Dis 1964;6:409-44

73. MacAnulty JH, Rahimtoola SH, Murphy ES, et al. A prospective study of sudden death in "high risk" bundle branch block. N Engl J Med 1978;299:209-15.
74. Denes P, Dhingra RC, Wu D, Wyndham CR, Amat-yLeon F, Rosen KM. Sudden death in patients with chronic bifascicular block. Arch Intern Med 1977; 137:1005-10.

75. Anderson RH, Wenick ACG, Losekoot TG, Becker AE. Congenitally complete heart block. Circulation 1977;56:90-101.

76. Stephan E. Hereditary bundle branch system defect. Survey of a family with four affected generations. $\mathrm{Am}$ Heart J 1978;95:89-95.

77. Gazes PC, Culler R, Taber E, Kelly RE. Congenital familial cardiac conduction defects. Circulation 1965;32:32-5.

78. Simonsen EE, Madesen EG. Four cases of right sided bundle branch block and one case of atrioventricular block in three generations of a family. Br Heart $J$ 1970;32:501-4.

79. Gault JH, Cantwell J, Lev M, Braunwald E. Fatal familial cardiac arrythmias. Histologic observations on the cardiac conduction system. Am J Cardiol 1972;29:548-53.

80. Lynch HT, Mohiuddin S, Moran J, et al. Hereditary progressive atrioventricular conduction defect. Am J Cardiol 1975;36:297-301.

81. Coumel P, Fidelle J, Lucet V, Attuel P, Bouvrain Y. Catecholamine-induced severe ventricular arrhythmias with Adams-Stokes syndrome in children: report of four cases. Br Heart J 1978; 40, suppl: 28-37.

82. James TN, Armstrong RS, Silverman J, Marshall TK. Clinicopathologic correlations. De subitaneis mortibus. VI. Two young soldiers. Circulation 1974;49:1239-46.

83. James TN, Mariley RJ Jr, Marriott HJ. De subitaneis mortibus. XI. Young girl with palpitations. Circulation 1974;51:743-8.

How to cite this article: Achalkar G. Sudden cardiac death: An autopsy study. J Diagn Pathol Oncol 2018;3(4):257-62. 